\title{
Effect of Ultra Low Cooling in Skin Temperature, Forearm Bloodflow and Electromyography
}

\author{
Yasuyuki Kikuchi, Michiko Igarashi, Tetsuo KatsuUra and Akira Okada \\ Department of Ergonomics, Faculty of Design, University of Chiba, Yayoi-cho, Chiba City, 260 Japan
}

\section{Introduction}

We examined the effects of the ultra low cooling on physical functions, that is, on skin temperature, forearm bloodflow and Electromyography (EMG). We have used the method of cooling in local region of the body surface to prevent the wound from pain and inflammation. Meanwhile, nowadays we have been taking the ultra low cooling locally and whole of body at $-110^{\circ} \mathrm{C} \sim-150^{\circ} \mathrm{C}$ to increase the blood flow and to prevent pain. So there are a few scientific data in the world in reference to the effect of low cooling, We have tried to get a few new data on those.

\section{Experiments}

2-1 The ultra low cooling apparatus

We used the CRYO-AIR GENERATOR MODEL L-10, made in NIPPON OXYGEN CO. Ltd. as the ultra low cooling apparatus. The MODEL L-10 was able to cool the dry air into $-150^{\circ} \mathrm{C}$ ultra low cooling air by liquid nitrogen. And consumption amount of liquid nitrogen is 15 litre per an hour.

\section{2-2 Method}

Seven heathy adult male students served these experiments as the subjects. They were from 21 to 24 years old. Before the experiment, they were instructed the experimental procedures and agreed with the exposure of ultra low temperature jet-air at these experiments. The subject is sitting on the chair easily for about $30 \mathrm{~min}$. before the jet-air exposure. And he was exposed to the cooled jet-air at $-110^{\circ} \mathrm{C}$ in the left forearm covered with the vinyl bag. The cooled jet-air flew inside of the vinyl bag till cooling the forearm homogeneously. From 1 min. before the beginning of exposure to an hour and a half after $180 \mathrm{sec}$. of ultra low cooling, the skin temperature, forearm bloodflow and electromyography of forearm flexion muscles were measured every 3 or $5 \mathrm{~min}$.

\section{Results}

3-1 Skin temperature

The cooling by jet-air at $-110^{\circ} \mathrm{C}$ brought the rapid decrease in cooled left forearm skin temperature to about $6^{\circ} \mathrm{C}$. But that in right forearm not to be cooled kept about $33^{\circ} \mathrm{C}$ during jet-air cooling of left forearm. After cooling for $180 \mathrm{sec}$., skin temperature in left forearm increased slowly and recovered to the nearly equal temperature at the state before cooling.

\section{3-2 Forearm bloodflow}

The forearm bloodflow was measured wiht murcury in rubber strain gauge every 3 or $5 \mathrm{~min}$., after $90 \mathrm{sec}$. jet-air cooling, for about $90 \mathrm{~min}$. Most of them increased their forearm bloodflow than those before cooling.

\section{3-3 Electromyography}

The maximal voluntary contractions (MVC) of all subjects were measured by the disc electrode inducing at forearm flexion muscles. Four min. sustained contraction at $40 \%$ MVC have gotten all out them. After "all out", their flexion muscles were cooled by jet-air in ultra low temperature for $180 \mathrm{sec}$, and EMGs of them by loading at $1 \mathrm{~kg}$ were induced by 4 -channel A/D recorder every 3 or 5 min. EMGs were analysed by Fast Foulie Transform (FFT). And slow wave ratio (SWR) was caliculated as a ratio of $49.98 \mathrm{~Hz}$ to $244.1 \mathrm{~Hz}$ area. The recovery from all out 


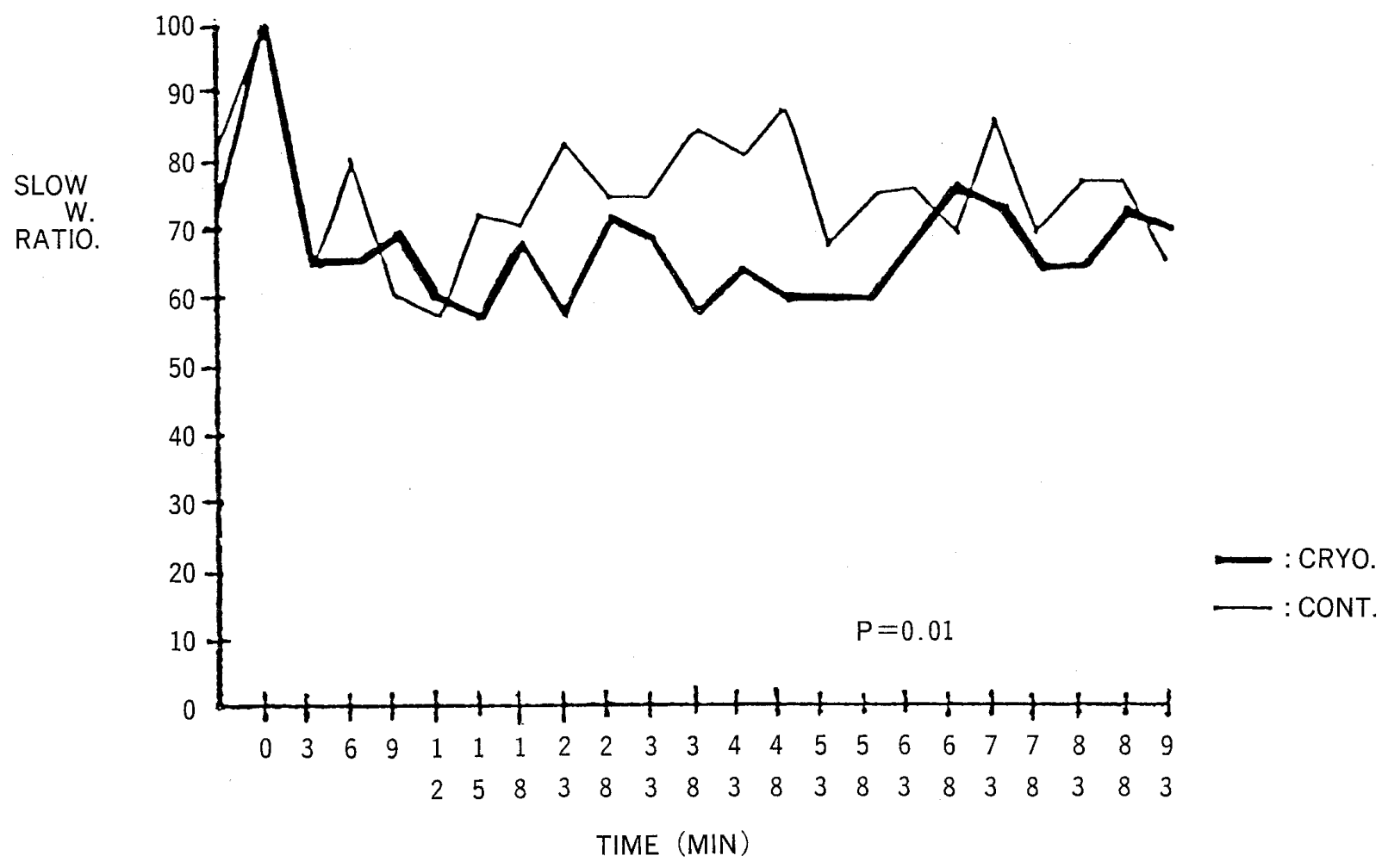

Fig. 1

was determined the SWR at that time. The SWR of experimental showed rapid recovery against that of control significantly as shown in Fig. 1.

\section{Discussion}

We could not see the rebound of skin temperature in this experiment as the result reported by Yamauchi, T. (1980). The forearm bloodflow in the most sujects increased in cooled forearm significantly. The results suggest, we think, the increase of the bloodflow in the deep tissue, not in the surface of skin, because the jet-air cooled the surface of the skin and got away the bloodflow to the deep tissue and muscle. And we think that the rapid recovery of EMG in cooling muscle from all out was caused with the more increase of bloodflow to the cooling muscle than no cooling one. We expect that this ultra low cooling method will be used and applicated in the field of physical and athletic training, rehabilitation and so on.

\section{References}

Barns WM, Mark RL, 1985 : Effect of localized hypothermia on maximal isometric grip strength. Amer. J. Physical Medicine, Vol. 64, 305-314.

Kitahara, H. et al., 1980 : Cryotherapy $\cdots$ Basic Research and Clinical Investigation. Sōgo Rehabilitation, Vol. 8, 209-215.

Pegg, S.M.H., Littler, T.R. et al. 1969 : A trial of ice therapy and exercise in chronic arthritis. Physiotherapy, Vol. 55, 51-56.

Peter GK, Stephen M. et al. 1979: The effect of actively increased muscle temperature of grip strength. Medicine and Science in Sports, Vol.2, 172-175.

Yamauchi, T. et al. 1977: Effect of localized ice therapy to chronic rheumatoid arthritis of the knee. Rehabilitation Medicine, Vol. 14, 47-54.

Yamauchi, T. et al. 1980: The Therapy of Very Low Temperature at $-180^{\circ} \mathrm{C}$ on Rheumatoid Joints. Physiotherapy, Vol. 9, 332.

(Received November 20, 1988) 